equilibrium constant $\kappa_{111}$ of $\mathrm{PbHL}^{2+}$ among the four amino acids. If the binding of $\mathrm{Pb}^{2+}$ through the carboxylate group occurs in $\mathrm{PbHL}^{2+}$, as was suggested previously[1], this trend is consistent with the fact that no difference in proton affinity of the carboxylate groups of the zwitter-ions is observed among the amino acids. On the contrary, it is obvious that the equilibrium constants $\beta_{101}$ of the three $C$-substituted derivatives are smaller than that of glycine in spite of the increased basicity $\left(K_{1}\right)$ of the nitrogen in the derivatives compared with glycine.

The distribution of the species as a function of $-\log \left[\mathrm{H}^{+}\right]$ calculated at $C_{\mathrm{Pb}}=0.005 \mathrm{~mol} \mathrm{dm}^{-3}$ and $C_{\mathrm{L}}=0.05 \mathrm{~mol} \mathrm{dm}^{-3}$ using their constants are drawn in Fig. 5.

\section{REFERENCES}

1. M. Maeda, Y. Tanaka and G. Nakagawa, J. Inorg. Nucl. Chem. 41, 705 (1979).

2. A. Olin, Acta Chem. Scand. 14,126 (1960).

MASUNOBU MAEDA

YOSHIHIRO TANAKA

GENKICHI NAKAGAWA

Department of Applied Chemistry

Nagoya Institute of Technology

Gokiso, Showa-ku, Nagoya 466

Japan

\title{
A mixed valence complex of gold with dimethyl sulfoxide
}

\author{
(Received 8 August 1980; received for publication 29 August 1980)
}

\begin{abstract}
A recent review of the chemistry of gold [1] indicated that while several true Au(II) compounds are known, most such compounds with a stoichiometry suggestive of $a+2$ oxidation state are mixed valence compounds containing an equal number of +1 and +3 ions. In our work on gold complexes with sulfoxides, we encountered a complex of empirical formula $\mathrm{Au}(\mathrm{DMSO}) \mathrm{Cl}_{2}$. We wish to report here the synthesis and partial characterization of this compound.
\end{abstract}

\section{EXPERIMENTAL}

Materials. Gold metal (99.99\%) was purified by dissolution in aqua regia followed by reduction with hydroquinone. The dimethyl sulfoxide- $d_{6}(99.5 \% \mathrm{D})$ was purchased from Merck and $\mathrm{Co}$. Other materials were of reagent grade.

The gold trichloride was prepared by three methods: the reaction of the metal with chlorine[2], the reaction of tetrachloroauric acid trihydrate with thionyl chloride [3], and by the evaporation of a concentrated perchloric acid solution of tetrachloroauric acid to fuming followed by vacuum drying of the filtered crystals at boiling toluene temperature. The product of the latter method was found to have superior properties in these reactions and required less time for preparation.

The gold tribromide was prepared by treatment of the powdered metal with liquid bromine followed by the removal of the excess bromine.

The trichloro(dimethyl sulfoxide)Au(III) was prepared as described elsewhere[4]. The bromo complex, tribromo(dimethyl sulfoxide)Au(III), was prepared by a similar method except a $10 \%$ solution of absolute ethanol in chloroform was used; decomp. $89-96^{\circ} \mathrm{C}$; Yield, $86 \%$. Anal. Calc. for $\mathrm{C}_{2} \mathrm{H}_{6} \mathrm{SOAuBr}$; $\mathrm{C}$, 4.67; H. 1.17: Au, 38.26\%. Found: C, 4.80; H, 1.14; Au, 38.43\%. The deuterated complexes were prepared by identical procedures.

Preparation of the mixed valence complex. This compound was prepared by two different methods. (a) Trichloro(dimethyl sulfoxide)Au(III) $(1.067 \mathrm{~g}, 2.771 \mathrm{mmole})$ was dissolved in $250 \mathrm{ml}$ of dried acetone. As the acetone was removed under reduced pressure an orange solid formed. This was filtered, washed with ether, and dried in vacuum: Yield, $0.326 \mathrm{~g}(34 \%)$. (b) To a solution of gold trichloride $(0.890 \mathrm{~g}, 2.93 \mathrm{mmol})$ in $200 \mathrm{ml}$ of $4 \%$ absolute ethanol in chloroform was added $2 \mathrm{ml}$ of dimethyl sulfoxide. The orange precipitate which formed was filtered, washed with ether, and dried in vacuum: Yield, $0.539 \mathrm{~g}(53 \%)$.

The products for both reactions were identical: decomp. 88$93^{\circ} \mathrm{C}$. Anal. Calc. for $\mathrm{C}_{2} \mathrm{H}_{6} \mathrm{SOAuCl}_{2}: \mathrm{C}, 6.94 ; \mathrm{H}, 1.75 ; \mathrm{Au}$, $56.93 \%$. Found: $\mathrm{C}, 6.71 ; \mathrm{H}, 1.82 ; \mathrm{Au}, 56.71 \%$. The deuterated analog was prepared in a similar manner.

All of the above gold compounds surveive best when prepared in anhydrous conditions and stored at low temperatures.
Analysis. Carbon, hydrogen and gold analyses were performed by Spang Microanalytical Laboratory, Eagle Harbor, Michigan. Physical measursurements. The IR spectra were recorded with a Perkin-Elmer 283 spectrophotometer over the range 4000 $200 \mathrm{~cm}^{-1}$. Samples were mulled in Nujol and placed on CsI plates covered with a thin film of polyethylene. UV-visible spectra were recorded with a Cary 118 spectrophotometer using $1 \mathrm{~cm}$ quartz cells. Magnetic susceptibility measurements were made on a Faraday balance.

\section{RESULTS AND DISCUSSION}

The simplest formula for the new compound, $\mathrm{Au}(\mathrm{DMSO}) \mathrm{Cl}_{2}$, first suggests that it is a complex of $\mathrm{Au}$ (II). This ion would have a $d^{9}$ electron configuration and should be paramagnetic as are the few other Au(II) complexes[1]. Magnetic susceptibility measurements on this compound show that it is diamagnetic $\left(\chi_{M}=-97 \times 10^{-6} \mathrm{cgs}\right)$ indicating that the compound is likely to be one of the more common mixed valence compounds containing both $A u(I)$ and $A u(I I I)$, both being diamagnetic. This partial reduction of the Au(III) starting material was in all likelihood caused by the alcohol or acetone [5] present in the system.

Also supporting the presence of both oxidation states is the UV spectra study. By putting the mixed valence complex into aqueous acid chloride solution $(0.6 \mathrm{M} \mathrm{HCl}$ and $0.5 \mathrm{M} \mathrm{NaCl})$ the $\mathrm{Au}(\mathrm{III})$ should be converted to the $\mathrm{AuCl}_{4}{ }^{-}$anion and the $\mathrm{Au}(\mathrm{I})$ should be stabilized as the $\mathrm{AuCl}_{2}^{-}$anion. The UV spectrum of this solution contains but a single absorption at $313 \mathrm{~nm}\left(\epsilon_{\max }=\right.$ $5.6 \times 10^{3}$ ) which is characteristic of $\mathrm{AuCl}_{4}^{-}[6]$. Quantitative determination of the amount of $\mathrm{Au}(\mathrm{III})$ present in this solution by a Beer's Law plot of standard Au(III) solutions in the same solvent shows that only half $(28.11 \%)$ the gold exists in this form. Again, the presence of equal amounts of $\mathrm{Au}(\mathrm{I})$ and Au(III) is supported.

The ESCA spectrum of the mixed valence complex is supportive of the presence of the +1 and +3 oxidation states. The mixed valence complex produces a $\mathrm{Au}\left(4 \mathrm{f}_{7 / 2}\right)$ line at a binding energy of $87.1 \mathrm{eV}$ which can be assigned to the +3 oxidation state and another line at $84.9 \mathrm{eV}$ which can be assigned to the +1 state [7-9]. The spectrum of the Au(III) complex, trichloro(dimethyl sulfoxide)Au(III), also has a line at a binding energy of $87.1 \mathrm{eV}$ while gold metal, as a reference. has its $\mathrm{Au}\left(4 \mathrm{f}_{7 / 2}\right)$ line at $83.8 \mathrm{eV}$.

The determination of the molecular weight of the mixed valence complex would specify the multiple of the empirical formula. However, the complex is insoluble in all common solvents and unstable with respect to reduction to gold metal when in contact with them. These problems make the cryoscopic determination of molecular weight impossible. Also the compound could only be prepared in a finely powdered state making 


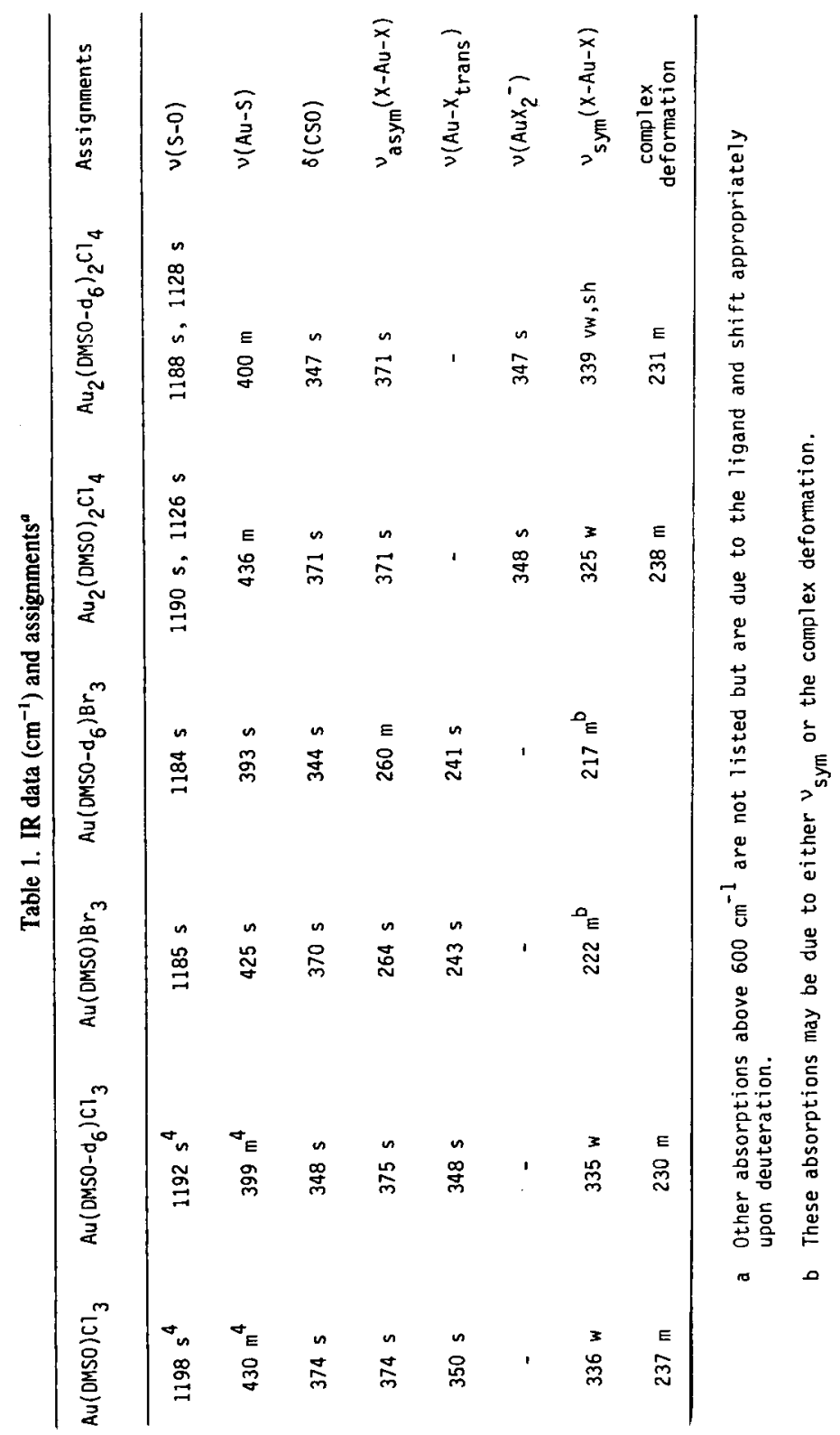


a crystal structure investigation impossible. Therefore, assuming the principie of simplicity, the following formula will be pursued: $\mathrm{Au}_{2}(\mathrm{DMSO})_{2} \mathrm{Cl}_{4}$.

The interpretation of the IR spectrum of the complex leads to a proposed formulation. The IR absorptions for the mixed valence complex and the other Au(III) complexes which are useful in the interpretation are given in Table 1 . An examination of the $\mathrm{S}-\mathrm{O}$ stretching frequencies show that they are all higher than that of the free ligand $\left(1053 \mathrm{~cm}^{-1}\right)$ which indicates that the sulfoxide is $\mathrm{S}$ bonded rather than $\mathrm{O}$ bonded in these compounds[10]. The occurrence of two $\mathrm{S}-0$ frequencies for the mixed valence complex suggests several interpretations: sulfoxides bonded to different sites, low symmetry complex (cis rather than trans), and crystal interactions in the solid state. Because of the possibility of the latter, the first two interpretations are uncertain. Therefore, little importance will be placed on the occurrence of two $\mathrm{S}-\mathrm{O}$ frequencies.

The far IR spectrum of the mixed valence complex appears to best support the formulation as $\left[\mathrm{Au}(\mathrm{DMSO}]_{2} \mathrm{Cl}_{2}\right]\left[\mathrm{AuCl}_{2}\right]$ in which the cation is in the trans configuration (Au(III) characteristically forms square planar complexes). The assignments in Table 1 are made on this basis. In the trans configuration only a single $\mathrm{Au}-\mathrm{S}$ stretching frequency (the $\mathrm{S}-\mathrm{Au}-\mathrm{S}$ asymmetric stretch) is IR allowed. The single absorption above $400 \mathrm{~cm}^{-1}$ is assigned to this vibration in that it appears in the same region as some other $\mathrm{Au}-\mathrm{S}[11] . \mathrm{Pt}-\mathrm{S}[12]$ and $\mathrm{Pd}-\mathrm{S}[13]$ vibrations. Its shif upon deuteration is also that expected from other results [13].

Two allowed $\mathrm{Au}-\mathrm{Cl}$ stretching vibrations should occur: one being the asymmetric $\mathrm{Cl}-\mathrm{Au}-\mathrm{Cl}$ stretch of the cation and the other due to the $\mathrm{AuCl}_{2}$ anion. The first of these should be very similar to that in the Au(III) complexes since substitution cis to this vibration should have little effect. The weak absorption at $325 \mathrm{~cm}^{-1}$ is assigned to the IR forbidden symmetric $\mathrm{Cl}-\mathrm{Au}-\mathrm{Cl}$ vibration. In other gold complexes this vibration is often not observed or believed coincident with another absorption [14]. The second strong absorption is that due to the $\mathrm{AuCl}_{2}{ }^{-}$anion which appears at $348 \mathrm{~cm}^{-1}$ and lies in the region expected for this vibration $[5,15,16]$. The Au(III) complex also has an absorption in this region which is assigned to the $\mathrm{Au}-\mathrm{Cl}$ stretching vibration trans to the sulfoxide [17, 18]. The Au(III)-bromo complex clearly shows a ligand frequency, the CSO deformation, at $370 \mathrm{~cm}^{-1}$ which shifts to $344 \mathrm{~cm}^{-1}$ upon deuteration [19]. In the chloro complexes these absorptions are coincident with $\mathrm{Au}-\mathrm{Cl}$ absorptions but can be observed by the inversion in intensities.

One final absorption appears in the far IR spectrum of all of these complexes in the region from 215 to $240 \mathrm{~cm}^{-1}$. At this low frequency it is likely to be due to a deformation mode of the complex itself [20]. In the bromo complex this absorption may be due to this vibration or the symmetric stretch.

Several other possible formulations for this mixed valence complex appear to be ruled out by the IR spectrum. One formulation suggested by analogy with similar $\mathrm{Pt}(\mathrm{II})$ and $\mathrm{Pd}(\mathrm{II})$ complexes is a bridged chloride species[21]. However, the $a b$ sence of an absorption near $300 \mathrm{~cm}^{-1}$ characteristic of a bridging chloride-metal vitration appears to eliminate this possibility $[22,23]$. The formulation $\left[\mathrm{Au}(\mathrm{DMSO})_{2}\right]\left[\mathrm{AuCl}_{4}\right]$ would produce but a single strong $\mathrm{Au}-\mathrm{Cl}$ vibration at about $356 \mathrm{~cm}^{-1}[15]$. A formulation similar to that proposed for complexes of the same stoichiometry with olefins and pyridine [24] would also appear to be ruled out because of the absence of a bridging chloride-metal vibration. The appearance of several ligand vibrations in the spectrum of the pyridine complex made the interpretation uncertain. Unfortunately, the bromo analog of the mixed valence complex could not be prepared since it would have been of great use in the interpretation of the IR data. Also unfortunate was the inability to obtain Raman spectra because of the decomposition of the compounds in the laser beam

One final piece of negative evidence in support of the trans formulation was the reaction of gold trichloride with the bis sulfoxide ligands, $\mathrm{CH}_{3} \mathrm{~S}(\mathrm{O}) \mathrm{CH}_{2} \mathrm{CH}_{2} \mathrm{~S}(\mathrm{O}) \mathrm{CH}_{3}$ and $\mathrm{CH}_{3} \mathrm{~S}(\mathrm{O}) \mathrm{CH}_{2} \mathrm{CH}_{2} \mathrm{CH}_{2} \mathrm{~S}(\mathrm{O}) \mathrm{CH}_{3}$. Under reaction conditions similar to those for the preparation of the mixed valence complex, the

*Author to whom correspondence should be addressed. reaction mixture first produced a yellow precipitate which then turned orange (the color of the mixed valence complex) but finally decomposed, all in the period of several minutes. This suggests a lack of stability of the cis complex which correlates with the fact that fewer cis complexes of Au(III) seem to be known than trans complexes [25]. All evidence appears to point to the trans-[Au(DMSO $\left.)_{2} \mathrm{Cl}_{2}\right]\left[\mathrm{AuCl}_{2}\right]$ formulation as the best one based on available data.

Acknowledgements-The authors wish to express their appreciation to the Campus Grants Committee of the University of Michigan-Dearborn for partial support of this work. Appreciation is also expressed to Steave Garrenstroom of the General Motors Research Laboratories for his assistance in obtaining the ESCA spectra. Special thanks is given to Carol Paquette for foreign literature translation.
Natural Sciences Department

University of Michigan-Dearborn

Dearborn

MI 48128

U.S.A.
B. A. SCHOENFELNER R. A. POTTS*

\section{REFERENCES}

1. H. Schmidbaur, Angew. Chem. Int. Ed. Engl. 15, 728 (1976).

2. G. Brauer, Ed., Handbook of Preparative Inorganic Chemistry. Academic Press, New York (1965).

3. D. B. Dell'Amico and F. Calderazzo, Gazz. Chim. Ital. 103 1099 (1973).

4. R. A. Potts. J. Inorg. Nucl. Chem. 34, 1749 (1972).

5. P. Braunstein and R. J. H. Clark, J. Chem. Soc., Dalton 1845 (1973).

6. A. K. Gangopadhayay and A. Chakrovorty, J. Chem. Phys 35, 2206 (1961).

7. H. Schmidbaur, J. R. Mandl, F. E. Wagner, D. F. Van deVondel and G. P. Van der Kelen, J. Chem. Soc., Chem. Commun. 170 (1976).

8. J. Knecht, R. Fischer, H. Overhof and F. Hensel, J. Chem. Soc., Chem. Commun. 905 (1978)

9. P. M. Th. M. van Attekum and J. M. Trooster, J. Chem. Soc. Dalton 201 (1980).

10. ${ }^{a}$ F. A. Cotton, R. Francis and W. D. Horrocks, J. Phys. Chem. 64, $1534(1960) ;{ }^{b} \mathrm{~F}$. A. Cotton and R. Francis, J. Am. Chem. Soc. 82, 2986 (1960).

11. V. H. Schmidbaur, R. Franke and J. Eberlein, Chem.-Ztg. 99 91 (1975).

12. B. F. G. Johnson and R. A. Walton, Spectrochim. Acta 22. 1853 (1966).

13. B. B. Wayland and R. F. Schramm, Inorg. Chem. 8, 971 (1969).

14. R. Usón, A. Laguna and J. Vicente, Rev. Acad. Cien. Exactas, Fis.-Quim. Nat. Zaragoza 31, 211 (1976).

15. G. E. Coats and C. Parkins, J. Chem. Soc. 421 (1963)

16. P. T. Beurskens, H. J. A. Blaauw, J. A. Cras and J. J. Steggerda, Inorg. Chem. 7, 805 (1968)

17. D. R. Williamson and M. C. Baird, J. Inorg. Nucl. Chem. 34. 3393 (1972)

18. E. A. Allen and W. Wilkinson, Spectrochim. Acta 28a, 2257 (1972).

19. C. V. Berney and J. H. Weber, Inorg. Chem. 7. 283 (1968).

20. D. A. Adams and W. R. Trumble, Inorg. Chem. 15, 1968 (1976).

21. W. Kitching, C. J. Moore and D. Doddress, Inorg. Chem. 9. $541(1970)$

22. R. J. Goodfellow, P. L. Goggin and L. M. Venanzi, J. Chem. Soc. (A) 1897 (1967)

23. D. M. Adams and R. G. Churchill, J. Chem. Soc. (A) 2141 (1968).

24. R. Hüttle, H. Reinheimer and K. Nowak, Chem. Ber. 101 , $3761(1968)$

25. G. Annibale, G. Natile, B. Pitteri and L. Cattalini, J. Chem. Soc. Dalton 728 (1978). 